\section{Comparison of metformin, gliclazide MR and rosiglitazone in monotherapy and in combination for type 2 diabetes}

\author{
Comparação de metformina, gliclazida MR e rosiglitazona em \\ monoterapia e em combinação para o diabetes tipo 2
}

Lucio Vilar ${ }^{12}$, Viviane Canadas², Maria Juliana Arruda ${ }^{2}$, Carla Arahata ${ }^{2}$, Rodrigo Agra ${ }^{2}$, Lisete Pontes ${ }^{2}$, Larissa Montenegro², Clarice Freitas Vilar', Lidiane Moura e Silva'2, José Luciano Albuquerque², Amaro Gusmão',2

\begin{abstract}
Objective: To compare the efficacy and tolerability of metformin, rosiglitazone and gliclazide MR as monotherapy and in combination in the treatment of type 2 diabetes. Subjects and methods: 250 patients treated with oral antidiabetic agents for at least 24 weeks in monotherapy or in combination therapy were included in this retrospective study. Results: As monotherapy the reduction of fasting plasma glucose (FPG), postprandial glycemia (PPG) and $\mathrm{HbA} 1 \mathrm{c}$ was similar with the three drugs after 24 weeks. Among patients on combination therapy, the reduction in HbA1c, FPG and PPG was significantly lower with rosiglitazone plus metformin, as compared to metformin plus gliclazide MR or gliclazide MR plus rosiglitazone. Patients treated with rosiglitazone achieved less favorable changes in lipid profile. Conclusion: In monotherapy all drugs were equally effective in improving glycemic control, whereas the combination of metformin plus gliclazide MR provided the best results concerning the improvement of both, glycemic control and lipid profile. Arq Bras Endocrinol Metab. 2010;54(3):311-8
\end{abstract}

Keywords

Metformin; glicazide MR; rosiglitazone

\section{RESUMO}

Objetivo: Comparar a eficácia e a tolerabilidade da metformina, rosiglitazona e gliclazida MR em monoterapia ou em combinação no tratamento do diabetes tipo 2. Sujeitos e métodos: 250 pacientes tratados com antidiabéticos orais por pelo menos 24 semanas, em monoterapia ou em terapia combinada, foram incluídos neste estudo retrospectivo. Resultados: Como monoterapia, a redução da glicemia de jejum (GJ), glicemia pós-prandial (GPP) e HbA1c foi similar com as três drogas, após 24 semanas. Entre os pacientes em terapia combinada, a redução da HbA1c, GJ e GPP foi significativamente menor com rosiglitazona e metformina, em comparação com metformina e gliclazida MR ou gliclazida MR mais rosiglitazona. Os pacientes tratados com rosiglitazona obtiveram mudanças menos favoráveis no perfil lipídico. Conclusão: Em monoterapia todos os medicamentos foram igualmente eficazes na melhora do controle glicêmico, enquanto a combinação de metformina e gliclazida MR proporcionou os melhores resultados relativos à melhoria de ambos, controle glicêmico e perfil lipídico. Arq Bras Endocrinol Metab. 2010;54(3):311-8

\section{Descritores}

Metformina; glicazida MR; rosiglitazona
${ }^{1}$ Centro de Diabetes e Endocrinologia de Pernambuco, Recife, PE, Brasil

${ }^{2}$ Serviço de Endocrinologia, Hospital das Clínicas, Universidade Federal de Pernambuco (UFPE), Recife, PE, Brasil

\section{INTRODUCTION}

$\mathrm{T}$ he main pathophysiologic mechanisms of hyperglycemia in type 2 diabetic patients involve insulin resistance, impaired insulin secretion and increased hepatic glucose output (1-3). The three main options among oral glucose-lowering drugs are metformin, sulphonylureas and thiazolidinediones (TZDs). They may be used as single-agent therapy, but the majority of patients will eventually require combination therapy to achieve an appropriate glycemic control (4-7). There 
has been some discussion on the best initial drug therapy for type 2 diabetes, but most authors choose metformin due to its efficacy, safety and lower cost (8-10).

Although metformin counteracts peripheral insulin resistance its major antihyperglycemic effect is to decrease hepatic glucose output $(11,12)$. Typically, metformin monotherapy will lower glycated hemoglobin $(\mathrm{HbAlc})$ by $\sim 1.5$ percentage points $(11,12)$. It is generally well tolerated with the most common adverse effects being gastrointestinal disturbances. The most feared complication is lactic acidosis, though extremely rare (less than 1 case per 100,000 treated patients) $(9,11)$. The major nonglycemic effect of metformin is either weight stability or modest weight loss, in contrast to most blood glucose-lowering medications $(5,6)$. The UKPDS demonstrated that metformin therapy significantly reduced the risk for microvascular and macrovascular diabetic complications $(13,14)$.

Sulphonylureas are widely used to treat type 2 diabetes because they stimulate insulin secretion by pancreatic beta-cells $(5,15)$. Hypoglycemia and weight gain are the main related inconveniences (4). Gliclazide is a second generation sulphonylurea while gliclazide-modified release (gliclazide MR) is a new formulation of this drug designed for once-daily administration $(16,17)$. As monotherapy, gliclazide MR provides a $0.9 \%-1.8 \%$ reduction in $\mathrm{HbAlc}(16)$. Intensive treatment of diabetes with gliclazide MR in the study ADVANCE resulted in significant reduction of microvascular complications (18). Gliclazide MR causes less hypoglycemia than chlorpropamide and glibenclamide $(16,19)$. In the GUIDE study (20), the rate of hypoglycemia was significantly lower with gliclazide MR as compared to glimepiride.

Rosiglitazone and pioglitazone are members of the TZD drug class. They are synthetic ligands that bind to the nuclear peroxisome proliferator-activated receptor-gamma (PPAR $\gamma)$ and reduce insulin resistance and glucose levels by increasing the sensitivity of muscle, fat, and liver to endogenous and exogenous insulin (21-24). When used as monotherapy TZDs reduced HbAlc levels by $0.5-1.4$ percentage points $(7,23)$. The most common adverse effects of TZDs are fluid retention and weight gain (24).

For patients who do not take insulin, accumulating evidence suggests that the combination therapy using oral antidiabetic agents with different mechanisms of action may be highly effective in achieving and maintaining target plasma glucose and HbAlclevels $(25,26)$. However, there has been some debate on which combination therapy would be more effective $(26,27)$.
The main objective of the present study was to evaluate the efficacy and tolerability of metformin, gliclazide MR and rosiglitazone as monotherapy and in combination in the management of type 2 diabetes.

\section{SUBJECTS AND METHODS}

\section{Study cohort}

A retrospective analysis of medical records was performed on patients with type 2 diabetes undergoing routine follow-up surveillance in the Division of Endocrinology of Hospital das Clínicas, Universidade Federal de Pernambuco, and in Pernambuco Diabetes and Endocrinology Center, located in Recife, Brazil, from 2000 to 2008. All patients treated with oral antidiabetic drugs for at least 24 weeks in monotherapy or in combination therapy without the concomitant use of lipid-lowering drugs were included in this study.

\section{Study design and assays}

The main objective of this study was to compare the efficacy of different treatments with oral glucose-lowering drugs regarding the improvement of glycemic control and lipid profile after 24 weeks. We also aimed at evaluating their effect on body weight and on the frequency of symptomatic hypoglycemia, gastrointestinal (GI) sideeffects, ankle edema, as well as cardiac complications.

Monotherapy with metformin, gliclazide MR or rosiglitazone was started in patients who did not respond to lifestyle intervention. Combination therapy was prescribed to patients whose monotherapy was not able to maintain $\mathrm{HbAlc}$ levels $<7 \%$. It consisted of dual therapy with metformin plus gliclazide MR, gliclazide $\mathrm{MR}$ and rosiglitazone, or metformin plus rosiglitazone.

Body mass index (BMI), HbAlc, fasting plasma glucose (FPG), postprandial plasma glucose (PPG), and lipid profile were evaluated at baseline and every three months afterwards. All plasmatic parameters were determined after a 12-hour overnight fast, except that of PPG that were obtained two hours after lunch. Venous blood samples were taken from all patients between 8 a.m. and 9 a.m. Total cholesterol (TC), HDLcholesterol, triglycerides ( $\mathrm{Tg}$ ), and plasma glucose were measured by immunoturbidimetric methods using commercial kits (Selectra Merck), with intra- and inter-assay coefficients of variation $(\mathrm{CV})<2 \%$. The LDL-cholesterol (LDL-C) concentration was calculated by the Friedewald formula (28). HbAlc levels were 
measured by a high-performance liquid chromatography method (DIAMAT, Bio-Rad, USA; normal values, 4.0\%-6.0\%), with intra- and inter-assay CV $<2 \%$. BMI was calculated as weight in kilograms divided by the square of height in meters.

Patients in use of lipid-lowering drugs were excluded from the study in order to allow a better interpretation of the effect of oral antidiabetic drugs on the lipid profile.

The study was performed according to the declaration of Helsinki and was approved by the local ethics committee. All study participants gave their informed consent for inclusion in the study.

\section{Statistical analysis}

In the analysis of qualitative variables, $\chi^{2}$ test or Fisher's exact test were used whenever necessary. Student's t-test or the analysis of variance (ANOVA) was performed for the comparative analysis of quantitative variables. Results are presented as mean values \pm SD. The value of $\mathrm{p}<0.05$ was considered statistically significant.

\section{RESULTS}

\section{Demographic, clinical and laboratorial features of} the patients

A total of 250 patients was enrolled in this study, of whom $130(52 \%)$ were females and 120 (48\%) males $(\mathrm{p}=0.689)$. Their age ranged from 38 to 65 years (mean, $50.2 \pm 19.2)$. According to the type of treatment, patients were subdivided into six groups: $60(24 \%)$ were treated with metformin (850-1000 mg twice daily), 40 (16\%) with gliclazide MR (60-90 mg/day), 25 (10\%) with rosiglitazone (4 mg twice daily), 65 (26\%) with gliclazide MR (60-90 mg/day) plus metformin (850$1.000 \mathrm{mg}$ twice daily), 30 (12\%) with metformin (850$1.000 \mathrm{mg}$ twice daily) and rosiglitazone (4 mg twice daily), and 30 (12\%) with gliclazide MR (60-90 mg/ day) plus rosiglitazone (4 mg twice daily).

As shown in table 1, BMI, baseline glycemic control and lipid profile did not differ significantly in patients submitted to monotherapy. The same was true for those that received combination therapy (Table 2).

\section{Effect of monotherapy on glycemic control, lipid profile and body weight}

The reduction of FPG, PPG and HbAlc was similar with the three drugs after 24 weeks (Table 3 ). However, at Week 12, the decrease of HbAlc levels was less pronounced with rosiglitazone (Figure 1). Conversely, the improvement in lipid profile was of lesser magnitude in the rosiglitazone group and similar in patients treated with metformin or gliclazide MR. Moreover, weight change greatly differed as there was a weight loss of $4.2 \pm 0.9 \mathrm{~kg}$ in the metformin group but a weight gain in the other groups $(\mathrm{p}<0.001)$.

\section{Effect of combination therapy on glycemic control, lipid profile and body weight}

As shown in table 4, the reduction of FPG, PPG and HbAlc, as well as the improvement in lipid profile, were less evident in patients treated with metformin plus rosiglitazone, whereas the improvement in lipid profile was stronger in the metformin-gliclazide MR group. Moreover, weight gain was significantly higher in patients who were given both gliclazide $\mathrm{MR}$ and rosiglitazone $(5.5 \pm 0.8 \mathrm{~kg} ; \mathrm{p}<0.001)$. The rate of patients who achieved FPG $<126 \mathrm{mg} / \mathrm{dL}$ was similar in the three groups, but the proportion of patients with HbAlc levels $<7 \%$ was significantly lower $(\mathrm{p}<0.001)$ in the metformin-rosiglitazone group. Figure 2 shows the effectiveness of the three drugs in reducing plasma glucose levels.

\section{Tolerability}

Metformin, gliclazide MR and rosiglitazone were well tolerated. As monotherapy, symptomatic hypoglycemia was reported by 2 of $40(5 \%)$ of the gliclazide MRtreated patients, but by none of those that used metformin or rosiglitazone. During combination therapy, symptomatic hypoglycemia occurred in 5 of $65(7.7 \%)$ patients treated with metformin and gliclazide $M R$, in 3 of $30(10 \%)$ subjects who were given rosiglitazone plus gliclazide MR, and in only 1 (3.3\%) of those who used metformin and rosiglitazone. The hypoglycemic episodes were mild, only happened in patients in use of $90 \mathrm{mg} /$ day of gliclazide MR and did not recur after improvement of dietary habits and/or dose reduction to $60 \mathrm{mg}$ /day of gliclazide MR. GI side-effects were more frequent in patients treated with metformin, both in monotherapy ( $11.6 \%$ versus $2.5 \%$ with gliclazide $\mathrm{MR}$ and $4 \%$ with rosiglitazone) and in combination therapy (12.3\% with metformin and gliclazide $\mathrm{MR}, 10 \%$ with metformin plus rosiglitazone, and $3.3 \%$ with gliclazide $\mathrm{MR}$ and rosiglitazone). Ankle edema was only found in patients who received rosiglitazone ( $8 \%$ in monotherapy, $10 \%$ with gliclazide MR and rosiglitazone, and 
$6.6 \%$ with metformin plus rosiglitazone). No cases of myocardium infarction or cardiovascular death was observed during the first 24 weeks of treatment. Pulmonary edema was diagnosed in 1 of 30 patients $(3.3 \%)$ treated with rosiglitazone alone by Week 20 .

The rate of patients who discontinued monotherapy due to side-effects was comparable for the three drugs: $1 / 40(2.5 \%)$ with gliclazide MR (skin rash), 3/60 (5\%) with metformin (GI side-effects), and 2/25 (8\%) with rosiglitazone (pulmonary edema, ankle edema, and weight gain). Discontinuation was not found in patients who were given combination therapy.

Table 1. Biochemical profile of patients before the introduction of monotherapy

\begin{tabular}{|c|c|c|c|c|}
\hline & $\begin{array}{l}\text { Metformin } \\
\text { Group } \\
(\mathrm{n}=\mathbf{6 0})\end{array}$ & $\begin{array}{c}\text { Gliclazide MR } \\
\text { Group } \\
(n=40)\end{array}$ & $\begin{array}{c}\text { Rosiglitazone } \\
\text { Group } \\
(n=25)\end{array}$ & p-value \\
\hline $\mathrm{BMI}\left(\mathrm{kg} / \mathrm{m}^{2}\right)$ & $28.1 \pm 1.5$ & $27.6 \pm 1.9$ & $27.4 \pm 2.5$ & 0.234 \\
\hline $\mathrm{FPG}(\mathrm{mg} / \mathrm{dL})$ & $165 \pm 13.1$ & $168.8 \pm 14.9$ & $160.4 \pm 16.8$ & 0.685 \\
\hline $\mathrm{PPG}(\mathrm{mg} / \mathrm{dL})$ & $177.2 \pm 15.4$ & $182.5 \pm 18.2$ & $171.6 \pm 16.3$ & 0.566 \\
\hline $\mathrm{HbA1c}(\%)$ & $7.9 \pm 2.6$ & $8.3 \pm 0.6$ & $7.8 \pm 2.2$ & 0.721 \\
\hline $\begin{array}{l}\text { Total cholesterol } \\
(\mathrm{mg} / \mathrm{dL})\end{array}$ & $257.2 \pm 30.4$ & $267.5 \pm 28.2$ & $251.6 \pm 26.8$ & 0.345 \\
\hline $\begin{array}{l}\text { HLD-cholesterol } \\
\text { (mg/dL) }\end{array}$ & $39.7 \pm 4.2$ & $38.6 \pm 5.2$ & $38.2 \pm 6.1$ & 0.731 \\
\hline $\begin{array}{l}\text { LDL-cholesterol } \\
\text { (mg/dL) }\end{array}$ & $143.3 \pm 10.7$ & $141.3 \pm 8.8$ & $139.8 \pm 7.1$ & 0.343 \\
\hline $\begin{array}{l}\text { Triglycerides } \\
(\mathrm{mg} / \mathrm{dL})\end{array}$ & $274.7 \pm 56.5$ & $269.8 \pm 53.9$ & $255.4 \pm 37.8$ & 0.092 \\
\hline
\end{tabular}

BMI: body mass index; FPG: fasting plasma glucose; PPG: postprandial plasma glucose

Table 2. Biochemical profile of patients before the introduction of combination therapy

\begin{tabular}{|c|c|c|c|c|}
\hline & $\begin{array}{c}\text { Gliclazide } \\
\text { MR- } \\
\text { Metformin } \\
\text { Group } \\
(n=65)\end{array}$ & $\begin{array}{c}\text { Gliclazide } \\
\text { MR- } \\
\text { Rosiglitazone } \\
\text { Group } \\
(\mathbf{n}=30)\end{array}$ & $\begin{array}{l}\text { Metformin- } \\
\text { Rosiglitazone } \\
\text { Group } \\
(\mathbf{n}=30)\end{array}$ & p-value \\
\hline $\mathrm{BMI}\left(\mathrm{kg} / \mathrm{m}^{2}\right)$ & $28.5 \pm 2.8$ & $27.9 \pm 2.3$ & $28.1 \pm 1.9$ & 0.756 \\
\hline $\mathrm{FPG}(\mathrm{mg} / \mathrm{dL})$ & $195.1 \pm 10.7$ & $193.8 \pm 8.8$ & $192.9 \pm 7.7$ & 0.910 \\
\hline PPG (mg/dL) & $205.2 \pm 19.4$ & $206.5 \pm 19.6$ & $204.1 \pm 20.5$ & 0.563 \\
\hline $\mathrm{HbA1c}(\%)$ & $9.3 \pm 0.6$ & $9.2 \pm 0.5$ & $9.2 \pm 0.8$ & 0.867 \\
\hline $\begin{array}{l}\text { Total cholesterol } \\
(\mathrm{mg} / \mathrm{dL})\end{array}$ & $277.2 \pm 36.8$ & $268.5 \pm 24.3$ & $266.2 \pm 26.2$ & 0.083 \\
\hline $\begin{array}{l}\text { HDL-cholesterol } \\
(\mathrm{mg} / \mathrm{dL})\end{array}$ & $38.6 \pm 6.6$ & $39.9 \pm 7.2$ & $38.2 \pm 8.1$ & 0.312 \\
\hline $\begin{array}{l}\text { LDL-cholesterol } \\
\text { (mg/dL) }\end{array}$ & $140.8 \pm 14.3$ & $142.3 \pm 12.8$ & $137.8 \pm 12.2$ & 0.095 \\
\hline $\begin{array}{l}\text { Triglycerides } \\
(\mathrm{mg} / \mathrm{dL})\end{array}$ & $282.5 \pm 66.3$ & $269.4 \pm 55.6$ & $265.8 \pm 40.2$ & 0.078 \\
\hline
\end{tabular}

BMI: body mass index; FPG: fasting plasma glucose; PPG: postprandial plasma glucose.

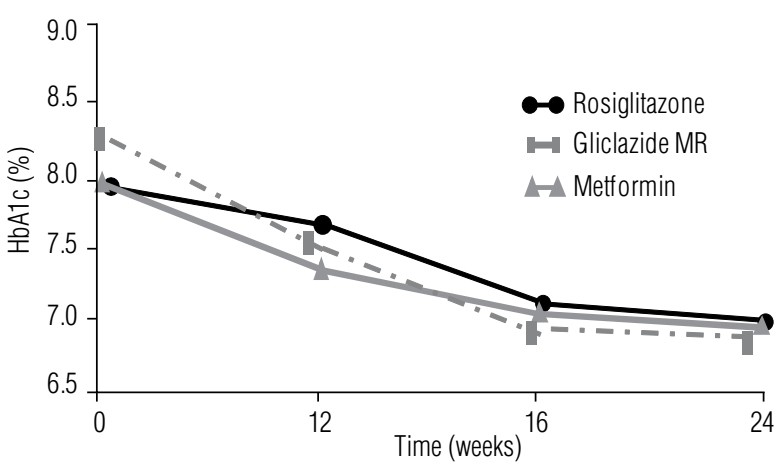

Figure 1. Comparative efficacy of monotherapy with metformin, gliclazide MR or rosiglitazone in the reduction of HbA1c at Weeks 12, 16 and 24.

\section{DISCUSSION}

Different studies have shown that metformin, sulphonylureas and TZDs provide similar reductions in $\mathrm{HbAlc}$ (4,29-31). However, there is evidence that long-term durability of glycemic control would be higher with TZDs. Indeed, the ADOPT study has shown a cumulative incidence of monotherapy failure at five years of $15 \%$ with rosiglitazone, $21 \%$ with metformin, and $34 \%$ with glyburide (31). Nevertheless, the most recent consensus statement for the management of type 2 diabetes from the American Diabetes Association (ADA) and the European Association for the Study of Diabetes (EASD) recommends metformin, due to its greater safety, as the best drug to be used together with lifestyle changes at the beginning of treatment (7).

Most patients with type 2 diabetes will eventually require the combination of two or more drugs with different mechanisms of action to achieve an appropriate glycemic control (25-27). Different regimens have been proposed, but the most commonly used is metformin combined with a sulphonylurea $(26,32,33)$. The rationale for the combination therapy with metformin and rosiglitazone or pioglitazone would be the fact that these drugs, despite being insulin sensitizers, target insulin resistance through different and complementary mechanisms $(34,35)$. Indeed, whereas metformin has a stronger effect to suppress hepatic glucose output, TZDs have a stronger effect to increase peripheral glucose disposal $(27,34,35)$. However, this therapy does not directly increase insulin secretion that is impaired in type 2 diabetes $(3,26)$. Conversely, the co-administration of a sulphonylurea with an insulin sensitizer enables both reduction of insulin resistance and stimulation of 
Table 3. Comparison of the effect of 24-week monotherapy on biochemical parameters and body weight

\begin{tabular}{|c|c|c|c|c|}
\hline & $\begin{array}{l}\text { Metformin Group } \\
\quad(n=60)\end{array}$ & $\begin{array}{l}\text { Gliclazide MR Group } \\
(\mathrm{n}=40)\end{array}$ & $\begin{array}{l}\text { Rosiglitazone Group } \\
(\mathbf{n}=\mathbf{2 0})\end{array}$ & p-value \\
\hline Mean change in weight $(\mathrm{kg})$ & $-4.2 \pm 0.9$ & $4.0 \pm 1.3$ & $3.2 \pm 0.8$ & $<0.001^{1}$ \\
\hline Mean reduction in FPG (\%) & $33.3 \pm 4.5$ & $34.0 \pm 6.8$ & $32.1 \pm 7.2$ & 0.945 \\
\hline Mean reduction in PPG (\%) & $32.0 \pm 5.5$ & $33.3 \pm 6.8$ & $30.8 \pm 4.7$ & 0.091 \\
\hline Mean reduction in $\mathrm{HbA1c}(\%)$ & $1.1 \pm 0.3$ & $1.2 \pm 0.2$ & $0.9 \pm 0.4$ & 0.088 \\
\hline Mean change in total cholesterol (\%) & $-7.7 \pm 2.2$ & $-6.2 \pm 2.5$ & $10.2 \pm 3.6$ & $<0.001^{2}$ \\
\hline Rate of patients with $\mathrm{PFG}<126 \mathrm{mg} / \mathrm{dL}(\%)$ & 40 & 47 & 38 & 0.720 \\
\hline Rate of patients with $\mathrm{HbA} 1 \mathrm{C}<7 \%(\%)$ & 27 & 30 & 25 & 0.956 \\
\hline Mean increase in HDL-cholesterol (\%) & $4.6 \pm 1.5$ & $4.4 \pm 1.2$ & $4.2 \pm 1.4$ & 0.427 \\
\hline Mean change in LDL-cholesterol (\%) & $-8.5 \pm 1.7$ & $-6.4 \pm 1.3$ & $12.4 \pm 2.8$ & $<0.001^{2}$ \\
\hline Mean change in triglycerides (\%) & $-9.4 \pm 1.8$ & $-6.3 \pm 1.4$ & $9.4 \pm 2.5$ & $<0.001^{2}$ \\
\hline
\end{tabular}

${ }^{1}$ Metformin versus gliclazide MR and rosiglitazone; ${ }^{2}$ Mettormin and gliclazide MR versus rosiglitazone.

$F P G$ = fasting plasma glucose; $P P G=$ postprandial plasma glucose .

Table 4. Comparison of the effect of 24-week combination therapy on biochemical parameters and body weight

\begin{tabular}{|c|c|c|c|c|}
\hline & $\begin{array}{c}\text { Metformin + gliclazide } \\
\text { MR Group } \\
(\mathrm{n}=65)\end{array}$ & $\begin{array}{l}\text { Gliclazide MR + } \\
\text { rosiglitazone Group } \\
(n=30)\end{array}$ & $\begin{array}{c}\text { Metformin + } \\
\text { rosiglitazone Group } \\
(n=30)\end{array}$ & p-value \\
\hline Mean increase in body weight $(\mathrm{kg})$ & $2.2 \pm 0.3$ & $5.5 \pm 0.8$ & $2.1 \pm 0.7$ & $<0.001^{1}$ \\
\hline Mean reduction in FPG (\%) & $58.2 \pm 5.3$ & $55.4 \pm 7.8$ & $46.2 \pm 4.7$ & $<0.001^{2}$ \\
\hline Mean reduction in $\mathrm{PPG}(\%)$ & $50.6 \pm 4.2$ & $48.2 \pm 6.6$ & $42.1 \pm 5.3$ & $<0.001^{2}$ \\
\hline Mean reduction in $\mathrm{HbA1c}(\%)$ & $1.7 \pm 0.2$ & $1.6 \pm 0.3$ & $1.2 \pm 0.4$ & $<0.001^{2}$ \\
\hline Rate of patients with $\mathrm{FPG}<126 \mathrm{mg} / \mathrm{dL}(\%)$ & 62 & 58 & 52 & 0.734 \\
\hline Rate of patients with $\mathrm{HbA} 1 \mathrm{C}<7 \%$ (\%) & 41.5 & 40 & 28 & $0.044^{2}$ \\
\hline Mean reduction in total cholesterol (\%) & $9.6 \pm 1.5$ & $3.2 \pm 0.7$ & $2.2 \pm 0.6$ & $<0.001^{3}$ \\
\hline Mean increase in HDL-cholesterol (\%) & $6.6 \pm 0.9$ & $6.4 \pm 0.7$ & $6.6 \pm 0.5$ & 0.485 \\
\hline Mean reduction in LDL-cholesterol (\%) & $8.6 \pm 1.4$ & $4.2 \pm 0.9$ & $3.2 \pm 0.8$ & $<0.001^{3}$ \\
\hline Mean reduction in triglycerides (\%) & $10.7 \pm 1.8$ & $5.7 \pm 1.4$ & $1.2 \pm 0.4$ & $<0.001^{3}$ \\
\hline
\end{tabular}

${ }^{1}$ Gliclazide MR + rosiglitazone versus gliclazide MR + mettormin and metformin + rosiglitazone; ${ }^{2}$ Metformin + rosiglitazone versus gliclazide MR + mettormin and gliclazide MR + rosiglitazone. ${ }^{3}$ Gliclazide MR + metformin versus gliclazide MR + rosiglitazone and metformin + rosiglitazone.

FPG = fasting plasma glucose; PPG = postprandial glucose; $\mathrm{Gl}$ = gastrointestinal.

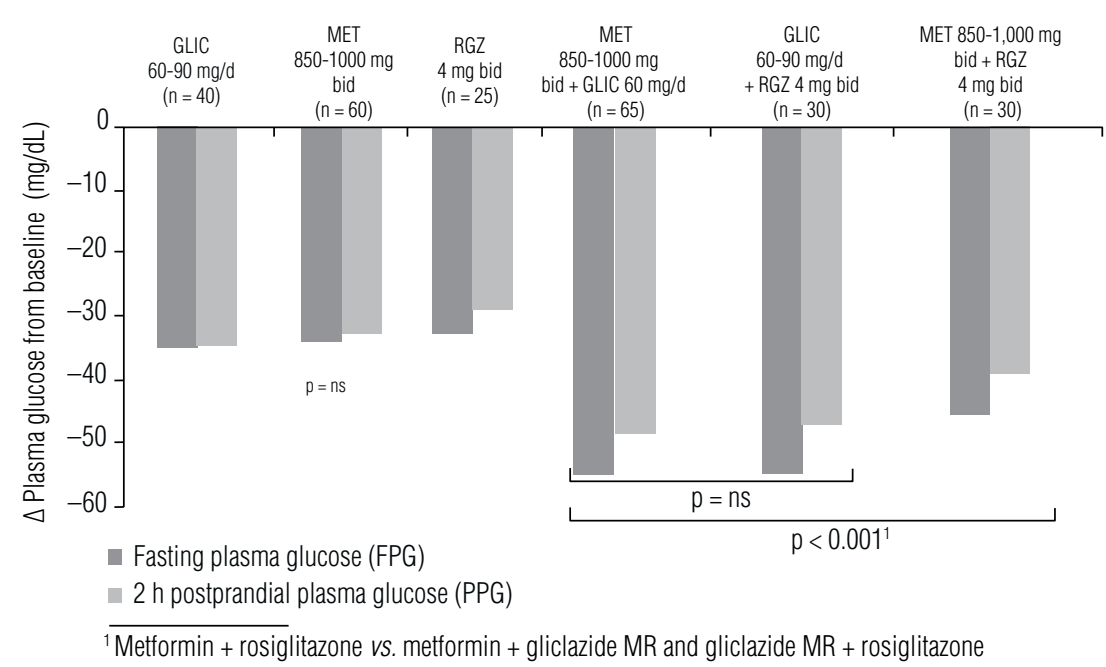

Figure 2. Mean reduction of plasma glucose levels with metformin (MET), gliclazide MR (GLIC) and rosiglitazone (RGZ) as monotherapy or in combination. The mean reduction of $F P G$ and PPG levels was significantly lower with MET + RGZ. 
insulin secretion from pancreatic $\beta$-cells $(5,8)$. In the UKPDS, the addition of metformin to a sulphonylurea increased the proportion of patients achieving $\mathrm{HbAlc}$ levels of less than $7 \%$ at 3 years from $21 \%$ to $33 \%$ (36).

In the present study, we found that therapy for 24 weeks with metformin, gliclazide MR or rosiglitazone as monotherapy was equally effective in improving glycemic control, a result that supports data from previous studies $(3-7,31)$. However, at Week 12, the improvement of glycemic control was less pronounced with rosiglitazone, suggesting a slower effect of this drug. This finding is consistent with the observation that the glucose-lowering effect of TZDs is usually more gradual, and may take more than three months to reach its maximum efficacy $(22-24,27)$. Furthermore, rosiglitazone-treated patients had higher levels of total cholesterol, LDL-c and triglycerides. It has been shown that, whereas pioglitazone usually produces a fall in triglycerides of at least $10 \%-20 \%$, with little change in LDL-c, rosiglitazone tends to increase both LDL-c and triglycerides levels (21-25,37). By contrast, the effects of metformin on lipid profile are modest, but usually favorable $(21,38)$.

On the assessment of combined therapies at Week 24 we found that the metformin-rosiglitazone combination was the less effective option in improving glycemic control $(\mathrm{p}<0.001)$ whereas the other treatments were equally efficient. Additionally, the improvement of lipid profile was significantly better $(\mathrm{p}<0.001)$ in the metformin-gliclazide MR group. Similar results were reported by Garber and cols. (39), who compared the combination of another sulphonylurea (glibenclamide) or rosiglitazone with metformin. In that study, more patients receiving metformin-glibenclamide attained a HbAlc concentration $<7.0 \%$ than did those in the metformin plus rosiglitazone group ( $60 \%$ versus $47 \%$ ) and had fasting plasma glucose levels $<126 \mathrm{mg} / \mathrm{dL}$ at week 24 (34 versus 25\%). In the study by Derosa and cols. (40), the improvement of lipid profile was also significantly greater in the metformin-glimepiride group whereas the reduction of plasma glucose and $\mathrm{HbAlc}$ was similar in patients treated with metformin plus glimepiride or metformin plus rosiglitazone. By contrast, in the RECORD study (41) patients treated with rosiglitazone plus metformin or a sulphonylurea achieved significantly lower values of $\mathrm{HbAlc}$ as compared to those that received the combination of metformin with a sulphonylurea, but they developed higher weight and LDL-c levels.
In the current study, the three drugs evaluated were well tolerated, either in monotherapy or in combination. While GI side-effects were more frequent among metformin-treated patients, symptomatic hypoglycemia and ankle edema were more prevalent with gliclazide MR and rosiglitazone, respectively. In clinical trials, the incidence of TZDs-associated edema varied from about $3.0 \%$ to $7.5 \%$, compared to $1.0 \%$ to $2.5 \%$ with placebo or other oral glucose-lowering agents (24). Weight gain induced by TZDs is usually modest (mean of $3.6 \mathrm{~kg}$ ) but may be excessive leading to discontinuation of treatment (42). TZDs are also associated with an increased incidence of fractures in women and perhaps in men $(7,41,43)$. Large trials, such as RECORD (41) and PROactive (42), showed that the use of TZDs results in a twofold increased risk for congestive heart failure $(41,42)$. Moreover, two meta-analyses have suggested a $30 \%-40 \%$ relative increase in risk for myocardium infarction in type 2 diabetic patients treated with rosiglitazone $(44,45)$. In the RECORD study, a non-statistically significant increased risk for myocardium infarction was noted in the rosiglitazone group (HR 1.14, 0.80-1.63) (41). However, low event rates might have precluded the statistical confirmation of significant risk, if present. Also, rosiglitazone was associated with higher LDL-c levels leading to an increased use of statins in the rosiglitazone group which might have reduced the incidence of cardiovascular events (46). Conversely, a meta-analysis of 19 randomized trials has indicated that pioglitazone is associated with a significantly lower risk of death, myocardial infarction, or stroke among a diverse population of patients with type 2 diabetes (47). In our series, there were no cases of myocardium infarction or deaths related to CVD. However, pulmonary edema developed in 1 of the 30 patients $(3.3 \%)$ who received rosiglitazone monotherapy. The joint consensus statement of ADA and EASD on the medical management of hyperglycemia in type 2 diabetes considers TZDs as less well-validated therapies and, as evidence currently favors pioglitazone, recommends the use of pioglitazone instead of rosiglitazone, when prescribing TZD therapy (7).

In conclusion, our data demonstrated that, as monotherapy metformin, rosiglitazone and gliclazide MR were equally effective in improving glycemic control whereas only rosiglitazone therapy was not associated with improvement of the lipid profile. Moreover, the combination of metformin plus gliclazide MR provided a greater improvement of glycemic control and lipid 
profile in comparison to the metformin-rosiglitazone group, as well as a more pronounced improvement of lipid profile as compared to the gliclazide $\mathrm{MR} /$ rosiglitazone combination therapy.

Disclosure: no potential conflict of interest relevant to this article was reported.

\section{REFERENCES}

1. Defronzo RA. Banting lecture. From the triumvirate to the ominous octet: a new paradigm for the treatment of type 2 diabetes mellitus. Diabetes. 2009;58(4):773-95.

2. Mizuno CS, Chittiboyina AG, Kurtz TW, Pershadsingh HA, Avery MA. Type 2 diabetes and oral antihyperglycemic drugs. Curr Med Chem. 2008;15(1):61-74.

3. Wajchenberg BL. Beta-cell failure in diabetes and preservation by clinical treatment. Endocr Rev. 2007;28(2):187-218.

4. American Association of Clinical Endocrinologists. The American Association of Clinical Endocrinologists Medical Guidelines for the Management of Diabetes Mellitus: the AACE system of intensive diabetes self-management - 2002 update. Endocr Pract. 2002;8 (suppl 1):40-82.

5. Inzucchi SE. Oral antihyperglycemic therapy for type 2 diabetes. JAMA. 2002;287(3):360-72.

6. Krentz AJ, Bailey CJ. Oral antidiabetic agents: current role in type 2 diabetes mellitus. Drugs. 2005;65(3):385-411.

7. Nathan DM, Buse JB, Davidson MB, Heine RJ, Holman RR, Sherwin $R$, et al. Management of hyperglycemia in type 2 diabetes: $A$ consensus algorithm for the initiation and adjustment of therapy: a consensus statement the American Diabetes Association and the European Association for the Study of Diabetes. Diabetes Care. 2006;29(8):1963-72.

8. Levetan C. Oral antidiabetic agents in type 2 diabetes. Curr Med Res Opin. 2007;23(4):945-52.

9. Cohen J, Colman P.Type 2 diabetes - the pharmacotherapy of glycaemic control and risk factor modification. Aust Fam Physician. 2006;35(6):380-4.

10. American Diabetes Association. Standards of medical care in Diabetes-2009. Diabetes Care. 2009;32(suppl 1):S13-S61.

11. Bailey CJ,Turner RC. Metformin. N Engl J Med. 1996;334(9):574-83.

12. DeFronzo RA, Goodman AM. Efficacy of metformin in patients with non-insulin-dependent diabetes mellitus. The Multicenter Metformin Study Group. N Engl J Med.1995;333(9):541-9.

13. UK Prospective Diabetes Study (UKPDS) Group. Effect of intensive blood glucose control with metformin on complication in overweight patients with type 2 diabetes (UKPDS 34). Lancet. 1998;352 (9131):854-65.

14. Holman RR, Paul SK, Bethel MA, Matthews DR, Neil HA. 10-year follow-up of intensive glucose control in type 2 diabetes. $\mathrm{N}$ Engl J Med. 2008;359(15):1577-89.

15. Lebowitz HE. Oral therapies for diabetic hyperglycemia therapy. Endocrinol Metab Clin North Am. 2001;30(4):909-33.

16. McGavin JK, Perry CM, Goa KL. Gliclazide modified release. Drugs. 2002;62(9):1357-64; discussion 1365-66.

17. Drouin P, Standl E; Diamicron MR Study Group. Gliclazide modified release: results of a 2-year study in patients with type 2 diabetes. Diabetes Obes Metab. 2004;6(6):414-21.

18. ADVANCE Collaborative Group, Patel A, MacMahon S, Chalmers J, Neal B, Billot L, Woodward M, et al. Intensive blood glucose control and vascular outcomes in patients with type 2 diabetes. N Engl J Med. 2008;358(24):2560-72.
19. Del Prato S, Pulizzi N.The place of sulfonylureas in the therapy for type 2 diabetes mellitus. Metabolism. 2006;55(5 Suppl 1):S20-7.

20. Schernthaner G, Grimaldi A, Di Mario U, Drzewoski J, Kempler P, Kvapil M, et al. GUIDE study: double-blind comparison of oncedaily gliclazide MR and glimepiride in type 2 diabetic patients. Eur J Clin Invest. 2004;34(8):535-42.

21. Bailey CJ. Treating insulin resistance in type 2 diabetes with metformin and thiazolidinediones. Diabetes Obes Metab. 2005;7(6):675-91.

22. Diamant M, Heine RJ. Thiazolidinediones in type 2 diabetes mellitus: current clinical evidence. Drugs. 2003;63(13):1373-405.

23. Wellington K. Rosiglitazone/ Metformin. Drugs. 2005;65(11):158192; discussion 1593-4.

24. Yki-Järvinen H.Thiazolidinediones. N Engl J Med. 2004;351(11):1106-8.

25. Bailey CJ, Bagdonas A, Rubes J, McMorn SO, Donaldson J, Biswas $\mathrm{N}$, et al. Rosiglitazone/metformin fixed-dose combination compared with uptitrated metformin alone in type 2 diabetes mellitus: a 24-week, multicenter, randomized, double-blind, parallel-group study. Clin Ther. 2005;27(10):1548-61.

26. Van Gaal LF, De Leeuw IH. Rational and options for combination therapy in the treatment of type 2 diabetes. Diabetologia. 2003;46 Suppl. 1: 44-50.

27. Bell DS. Type 2 diabetes mellitus: what is the optimal treatment regimen? Am J Med. 2004;116(Suppl. 5A):23S-29S.

28. Friedewald WT, Levy RJ, Fredrickson DS. Estimation of the concentration of low density lipoprotein in plasma, without use of the preparative ultracentrifuge. Clin Chem. 1972;18(6):499-502.

29. United Kingdom Prospective Diabetes Study (UKPDS). Intensive blood-glucose control with sulphonylureas or insulin compared with conventional treatment and risk of complications in patients with type 2 diabetes (UKPDS 33). Lancet. 1998;352(9131):837-53.

30. Gaede P, Vedel P, Larsen N, Jensen GV, Parving HH, Pedersen O. Multifactorial intervention and cardiovascular disease in patients with Type 2 Diabetes. N Engl J Med. 2003;348(5):383-93.

31. Kahn SE, Haffner SM, Heise MA, Herman WH, Holman RR, Jones NP, et al.; ADOPT Study Group. Glycemic durability of rosiglitazone, metformin, or glyburide monotherapy. N Engl J Med. 2006;355(23):2427-43.

32. Green J, Feinglos M. New combination treatments in the management of diabetes: focus on sitagliptin-metformin. Vasc Health Risk Manag. 2008;4(4):743-51.

33. Raskin P, Lewin A, Reinhardt R, Lyness W; Repaglinide/Metformin Fixed-Dose Combination Study Group. Twice-daily dosing of a repaglinide/metformin fixed-dose combination tablet provides glycaemic control comparable to rosiglitazone/metformin tablet. Diabetes Obes Metab. 2009 May 19. [Epub ahead of print]

34. Rosenstock J, Rood J, Cobitz A, Biswas N, Chou H, Garber A. Initial treatment with rosiglitazone/metformin fixed-dose combination therapy compared with monotherapy with either rosiglitazone or metformin in patients with uncontrolled type 2 diabetes. Diabetes Obes Metab. 2006;8(6):650-60.

35. Kaku K. Efficacy and safety of therapy with metformin plus pioglitazone in the treatment of patients with type 2 diabetes: a double-blind, placebo-controlled, clinical trial. Curr Med Res Opin. 2009;25(5):1111-9.

36. UKPDS 28. A randomized trial of efficacy of early addition of metformin in sulphonylurea-treated Type 2 diabetes. UK Prospective Diabetes Study (UKPDS) Group. Diabetes Care. 1998;21(1):87-92.

37. Chappuis B, Braun M, Stettler C, Allemann S, Diem P, Lumb PJ, et al. Differential effect of pioglitazone (PGZ) and rosiglitazone (RGZ) on postprandial glucose and lipid metabolism in patients with type 2 diabetes mellitus: a prospective, randomized crossover study. Diabetes Metab Res Rev. 2007;23(5):392-9. 
38. Granberry MC, Fonseca VA. Cardiovascular risk factors associated with insulin resistance: effects of oral antidiabetic agents. Am J Cardiovasc Drugs. 2005;5(3):201-9.

39. Garber A, Klein E, Bruce S, Sankoh S, Mohideen P. Metformin-glibenclamide versus metformin plus rosiglitazone in patients with type 2 diabetes inadequately controlled on metformin monotherapy. Diabetes Obes Metab. 2006;8(2):156-63.

40. Derosa G, D’Angelo A, Ragonesi PD, Piccinni MN, Pricolo F, Salvadeo SA, et al. Metformin-pioglitazone and metformin-rosiglitazone effects on non-conventional cardiovascular risk factors plasma level in type 2 diabetic patients with metabolic syndrome. J Clin Pharm Ther. 2006;31(4):375-83.

41. Home PD, Pocock SJ, Beck-Nielsen H, Curtis PS, Gomis R, Hanefeld $M$, et al.; RECORD Study Team. Rosiglitazone evaluated for cardiovascular outcomes in oral agent combination therapy for type 2 diabetes (RECORD): a multicentre, randomised, open-label trial. Lancet. 2009;373(9681):2125-35.

42. Dormandy JA, Charbonnel B, Eckland DJ, Erdmann E, Massi-Benedetti M, Moules IK, et al.; PROactive investigators. Secondary prevention of macrovascular events in patients with type 2 dia- betes in the PROactive Study (PROspective pioglitAzone Clinical Trial In macroVascular Events): a randomised controlled trial. Lancet. 2005;366(9493):1279-89.

43. Kahn SE, Zinman B, Lachin JM, Herman WH, Holman RR, Kravitz BG, et al.; Diabetes Outcome Progression Trial (ADOPT) Study Group. Rosiglitazone-associated fractures in type 2 diabetes: an Analysis from A Diabetes Outcome Progression Trial (ADOPT). Diabetes Care. 2008;31(5):845-51.

44. Nissen SE, Wolski K. Effect of rosiglitazone on the risk of myocardial infarction and death from cardiovascular causes. $\mathrm{N}$ Engl J Med. 2007;356(24):2457-71. [Erratum, N Engl J Med. 2007;357 (1):100.]

45. Singh S, Loke YK, Furberg CD. Long-term risk of cardiovascular events with rosiglitazone: a meta-analysis. JAMA. 2007;298(10):1189-95.

46. Retnakaran R, Zinman B. Thiazolidinediones and clinical outcomes in type 2 diabetes. Lancet. 2009;373(9681):2088-90.

47. Lincoff AM, Wolski K, Nicholls SJ, Nissen SE. Pioglitazone and risk of cardiovascular events in patients with type 2 diabetes mellitus: a meta-analysis of randomized trials. JAMA. 2007;298(10):1180-8. 